\title{
Fair Apportionment in the View of the Venice Commission's Recommendation
}

\author{
Péter Biróa,b, László Á. Kóczy ${ }^{\mathrm{a}, \mathrm{c}, *}$, Balázs Sziklai ${ }^{\mathrm{a}}$ \\ a'Momentum' Game Theory Research Group, Centre for Economic and Regional Studies, \\ Hungarian Academy of Sciences. Budaörsi 45., H-1112 Budapest, Hungary. \\ ${ }^{b}$ Department of Operations Research and Actuarial Sciences, Corvinus University of \\ Budapest, Hungary \\ ${ }^{c}$ Keleti Faculty of Business and Management, Óbuda University, Budapest
}

\begin{abstract}
The Venice Commission in its Code of Good Practice in Electoral Matters specifies that (single-seat) constituencies should be drawn so that the size difference of a constituency's size from the average should not exceed a fixed limit while its borders must not cross the borders of administrative regions, such as states or counties.
\end{abstract}

Assuming that constituencies are of equal size within each of the administrative regions, the problem is equivelent to the apportionment problem, that is, the proportional allocation of voting districts among the administrative regions. We show that the principle of maximum admissible departure is incompatible with common apportionment properties, such as monotonicity and Hare-quota.

When multiple apportionments satisfy the smallest maximum admissible departure property we find a unique apportionment by the repeated application of the property. The allotment such that the differences from the average district size are lexicographically minimized can be found using an efficient algorithm. This apportionment rule is a well-defined allocation mechanism compatible with and derived from the recommendation of the Venice Commission. Finally, we compare this apportionment rule with mainstream mechanisms using data from

\footnotetext{
${ }^{*}$ Corresponding author

Email addresses: biro.peter@krtk.mta.hu (Péter Biró), koczy@krtk.mta.hu (László Á. Kóczy), sziklai.balazs@krtk.mta.hu (Balázs Sziklai)
}

The final publication is available at Elsevier via http://dx.doi.org/10.1016/j.mathsocsci.2015.06.001 
Hungary, Germany and the United States.

Keywords: apportionment, elections, Venice Commission, lexicographic ordering

\section{Introduction}

Fair representation is the cornerstone of representative democracies. The idea that each congressmen should represent the same number of citizens is as old as the United States. We study the so-called apportionment problem (for 5 recent texts see Pukelsheim, 2014 or Chapter 1 of Kubiak, 2009): sharing a given number of seats among a given set of regions with known populations in a fair way and look for mechanisms that provide a unique solution to each problem. Such a unique solution leaves no room for political bargaining and manipulation in designing or updating the legal framework for elections.

The stakes at the elections are very high and therefore the codification of any electoral law should be done with great care. Seemingly an easy problem, establishing electoral districts ${ }^{1}$ with equal numbers of voters becomes nontrivial, when they must fit into the existing administrative structure of a country. There are alternative ways to approach the problem, generating a constant debate even in countries with well-established democracies such as the United States. (For a comprehensive historical overview see Balinski and Young, 1982). A new entrant to this debate, the European Commission for Democracy through Law, better known as the Venice Commission published a comprehensive guidebook on good electoral laws in 2002. The Code of Good Practice in Electoral Matters (Venice Commission, 2002a) - consequently used in reviewing Albania's and Estonia's electoral law in 2011 (OSCE/ODIHR, 2011, Venice Commission and OSCE/ODIHR, 2011) and forming an apparent basis to the modifications

\footnotetext{
${ }^{1}$ Voting terminology differs from country to country: We use electoral district or constituency interchangeably to refer to a geographical area, the people and especially the voters living there who elect one or more representatives. For simplicity we focus on single-seat voting districts.
} 
Hungary introduced to in its electoral law in 2012 -, contains original recommendations for a good practice of apportionment.

"Equality in voting power, where the elections are not being held in one single constituency, requires constituency boundaries to be drawn in such a way that seats in the lower chambers representing the people are distributed equally among the constituencies, in accordance with a specific apportionment criterion, e.g. the number of residents in the constituency, the number of resident nationals (including minors), the number of registered electors, or possibly the number of people actually voting ... Constituency boundaries may also be determined on the basis of geographical criteria and the administrative or indeed historic boundary lines, which often depend on geography ... The maximum admissible departure from the distribution criterion adopted depends on the individual situation, although it should seldom exceed $10 \%$ and never 15\%, except in really exceptional circumstances (a demographically weak administrative unit of the same importance as others with at least one lower-chamber representative, or concentration of a specific national minority)." (Venice Commission, 2002a, $\S \S 13-15$ in Section 2.2)

Similar conditions are common, though not universal. In Georgia, where the electoral law of 1999 did not set rules about the sizes of constituencies, the number of voters per (single-seat) constituency ranged from some 3,600 voters in the Lent'ekhi district or 4,200 in the Kazbegi districts to over 138,000 in Kutaisi City giving multiple times more influence to voters from Lent'ekhi or the Kazbegi district than to those from Kutaisi City. The report of the Venice Commission arrived to the conclusion that huge deviations like this question the fairness of the whole election process (Venice Commission, 2002b). On the other hand, in the United States, theoretically, no deviations from the equality of constituencies are permitted; "other common thresholds are 5 percent (e.g., New Zealand, Albania, and Yemen); 10 percent (e.g., Australia, Italy, and the 
Ukraine); 15 percent (e.g., Armenia, Germany, and the Czech Republic) and 20 percent (e.g., Zimbabwe and Papua New Guinea). In Canada, the independent commissions charged with creating federal electoral districts are allowed to deviate by up to 25 percent from the provincial quotas, and even more under 'extraordinary circumstances'." (Handley, 2007). In Singapore the tolerance is $30 \%$; a recent proposal to reform the constituency map of the United Kingdom worked with a $5 \%$ permitted deviation from the average size (Balinski et al. 60 2010). The draft version of the 2012 electoral law of Hungary adopted the Venice Commission's recommendation almost word by word, but the 10-15\% maximum admissible departure between the population of any two constituency turned out to be infeasible given the actual size of the parliament and the populations of counties, if the constituencies cannot extend over county borders Biró et al. 65 2012 Bodnár, 2012). Even with the subsequent relaxation, allowing a 15\% (at most 20\%) departure from the average size of constituencies in the final version, the requirements were just met.

We take this maximum admissible departure property and compare it with the properties that had been used to evaluate and judge apportionment methods. As generally there may be more than one apportionments satisfying this property, we look for apportionments where the maximum admissible departure is the lowest, then applying the same idea to the second largest difference, and so on. The naturally emerging leximin apportionment is unique (up to symmetries) and can be calculated using an efficient algorithm.

We focus on the simple setting where (1) districts elect single representatives, (2) forming even constituencies within each of the regions is possible and (3) representation is proportional. The results generalise directly to multirepresentative districts. In designing the constituencies of a region not only the obvious integer problem (such as having two equal-sized constituencies in a reso gion with odd population), but contiguity requirements and town and township boundaries too, create additional constraints that make the actual apportionment a little less equal. How the actual borders of the constituencies are drawn is yet another question. The strategic, manipulative design of voting districts, 
known as gerrymandering Gul and Pesendorfer, 2010, Chambers and Miller. 2013) may happen with equally-sized districts, too. Last, we assume that the role of regions, states or counties is purely administrative and that they do not have sovereign interests. If they do, representatives are likely to vote in blocks and the effect on voting outcomes is no longer proportional to the size of the region's population, hence in larger problems there is a systematic bias in favour of larger regions. The literature on voting power and power indices (Penrose, 1946, Shapley and Shubik, 1954 and Banzhaf, 1965, for a recent survey see Felsenthal and Machover, 1998) study weighted voting situations such as the European Council of Ministers (Kóczy, 2011), Penrose's square root law (Penrose, 1946) or the degressive proportionality (Laslier, 2012, Koriyama et al.

95 2013) of the base+prop method (Pukelsheim, 2007) promoted in the Cambridge Compromise (Grimmett, 2012, Grimmett et al., 2011, Rose et al., 2012) and give explicit recommendations on how to adjust for this. With the appropriate population adjustments, these problems, however, can be reduced to proportional allocation.

In the following we first formalise the apportionment problem and critically discuss the (smallest) maximum admissible departure property. In Sections 4 and 5 we introduce the leximin solution for apportionment problems and then apply this to apportionment problems from various countries: we compare the leximin solution with the actual apportionment as outlined by the new electoral law of Hungary and make a similar comparison for the German Bundestag and the United States House of Representatives. We conclude with a more technical discussion of the related apportionment methods in literature.

\section{The apportionment problem, mechanisms and their properties}

An apportionment problem $(\mathbf{p}, H)$ is a pair consisting a vector

$$
\mathbf{p}=\left(p_{1}, p_{2}, \ldots, p_{n}\right)
$$

of state populations, where $P=\sum_{i=1}^{n} p_{i}$ is the population of the country and $H$ denotes the number of seats in the legislature or House. Our task is to de- 
termine the non-negative integers $a_{1}, a_{2}, \ldots, a_{n}$ with $\sum_{i=1}^{n} a_{i}=H$ representing the number of constituencies in states $1,2, \ldots, n$.

Let $\mathbf{p} \in \mathbb{N}_{+}^{n}$ and $\mathbf{a} \in \mathbb{N}^{n}$ be the $n$-dimensional vectors that contain the population sizes and the allotted number of seats respectively (where $\mathbb{N}_{+}=$ $\{1,2,3, \ldots\})$. An apportionment method or rule is a function $M$ that assigns an allotment for each apportionment problem $(\mathbf{p}, H)$. The fraction $\frac{p_{i}}{P} H$ is called the respective share of state $i$. Throughout the paper we will employ the following notation: let $\mathbf{x}, \mathbf{y} \in \mathbb{R}^{n}$, we say that $\mathbf{x} \geq \mathbf{y}$ if $x_{i} \geq y_{i}$ for $i=1,2, \ldots, n$.

In the following we introduce several properties of apportionments. of the states are hardly ever integer numbers. However if such case occurs i.e. the fractions $a_{i}=\frac{p_{i}}{P} H$ are integers for all $i \in\{1, \ldots, n\}$ then the allotment $\mathbf{a}$ is said to have the exact quota property.

In any other case taking one of the nearest integers to the exactly proportional share is a natural choice. An allotment a satisfies lower (upper) quotas, if no state receives less (more) constituencies than the lower (upper) integer part of its respective share, that is $a_{i} \geq\left\lfloor\frac{p_{i}}{P} H\right\rfloor$ for all $i \in\{1, \ldots, n\}$ and $a_{i} \leq\left\lceil\frac{p_{i}}{P} H\right\rceil$ for all $i \in\{1, \ldots, n\}$, respectively.

An allotment satisfies the quota property if it satisfies both upper and lower quota. Similarly we say that an apportionment method $M(\mathbf{p}, H)$ satisfies lower (upper) quota if for any apportionment problem $(p, H), M(\mathbf{p}, H)_{i} \geq\left\lfloor\frac{p_{i}}{P} H\right\rfloor$ or $M(\mathbf{p}, H)_{i} \leq\left\lceil\frac{p_{i}}{P} H\right\rceil$ respectively for all $i \in\{1, \ldots, n\}$ and satisfies quota if it satisfies both of them.

Monotonicity. The individual states should not lose seats when more seats are available in the House. Formally:

Definition 1. An apportionment rule $M$ is house-monotonic if $M\left(\mathbf{p}, H^{\prime}\right) \geq$ $M(\mathbf{p}, H)$ for any apportionment problem $(\mathbf{p}, H)$ and House sizes $H^{\prime}>H$.

A scenario where increasing the House size would decrease the number of seats allotted to a state is often considered undesirable, perhaps even paradoxi- 
Smallest maximum admissible departure property. The next property characterizes the recommendation ${ }^{2}$ made by the Venice Commission $(2002 \mathrm{a})$. Let $\bar{a}=\frac{P}{H}$

\footnotetext{
${ }^{2}$ Although the Venice Commission is flexible on what kind of data should be the distribution criterion based on, it is clear that the difference from the average value is to be minimized. The most common interpretation is that there should be a limit on the allowable departure of the average number of registered voters per constituency (see Handley (2007)). We follow this practice as well, nevertheless our results hold in general, irrespective of the chosen reference data.
} 
denote the average size of a constituency, let $\delta_{i}$ be the difference in percentage, displayed by the constituencies of state $i$ and let $d_{i}$ be its absolute value. Formally

$$
\delta_{i}=\frac{\frac{p_{i}}{a_{i}}-\bar{a}}{\bar{a}} \quad \text { and } \quad d_{i}=\left|\delta_{i}\right|
$$

Definition 3. An apportionment rule $M$ satisfies the q-fixed maximum admissible departure property if $\left|\frac{\frac{p_{i}}{M(\mathbf{p}, H)_{i}}-\bar{a}}{\bar{a}}\right| \leq q$ for any apportionment problem $(p, H)$ and for each $i \in\{1, \ldots, n\}$.

As we pointed out in the introduction European electoral laws impose a fixed limit on $\max _{i \in\{1, \ldots, n\}}\left\{d_{i}\right\}$ rather than minimizing it. The Venice Commission follows this practice as well. It can happen, however, that, given an apportionment problem, no allotment exists that satisfy a certain limit, while an allotment with smallest maximum admissible departure always exists. Thus we focus on the latter concept. For a given apportionment problem $(\mathbf{p}, H)$ let ${ }_{175} \alpha_{(\mathbf{p}, H)}$ be the smallest maximum admissible departure that can be achieved with an allotment i.e.

$$
\alpha_{(\mathbf{p}, H)}=\min _{\mathbf{a} \in A(n, H)} \max _{i \in\{1, \ldots, n\}}\left\{d_{i}\right\}
$$

where $A(n, H)$ denotes the set of $n$-dimensional non-negative vectors for which the sum of the coordinates is $H$.

Definition 4. An apportionment rule $M$ satisfies the smallest maximum admis180 sible departure property if $\left|\frac{\frac{p_{i}}{M(\mathbf{p}, H)_{i}}-\bar{a}}{\bar{a}}\right| \leq \alpha_{(\mathbf{p}, H)}$ for any apportionment problem $(p, H)$ and for each $i \in\{1, \ldots, n\}$.

The philosophy behind the quota and the smallest maximum admissible departure property is very similar, but not quite the same. The quota specifies how many seats a state should receive at least and at most. If a state gets less than its lower quota, then the allotment can be considered somewhat unfair from the 
point of view of that particular state. The smallest maximum admissible departure property is concerned rather with the individual voter. If the population sizes of the constituencies differ too much so does the voters' influence. Not surprisingly, the quota property plays more central role in the U.S. where the states are large and highly independent. In Europe, where the countries consist of small and in some sense uniform counties, the smallest maximum admissible departure property is more accepted.

\section{The smallest maximum admissible departure property}

In this section we review the basic features of the smallest maximum admisand write simply $\alpha$. First let us note that $\alpha$ is not monotone decreasing in the House size. To see this consider the allocation problem where $p=(100,200)$ and let $H=3$. Then it is possible to distribute the seats according to the exact quota thus $\alpha=0$. However an increase of $H$ by 1 renders both $d_{1}$ and $d_{2}$ positive.

\subsection{Upper bounds on the smallest maximum admissible departure}

Obviously $d_{i}$ is the smallest if state $i$ receives either its lower or upper quota, although it matters which one. Note that the closest integer to the respective share not always yields the smallest difference from the average. Let us elaborate on this relationship a little bit further. Let $l_{i}=\left\lfloor\frac{p_{i}}{P} H\right\rfloor$ and $u_{i}=\left\lceil\frac{p_{i}}{P} H\right\rceil$, respectively denote these quotas of state $i$ and let $\beta_{i}$ denote the minimum difference achievable for state $i$. The maximum of these $\beta_{i}$ values, denoted by $\beta$, is a natural lower bound for $\alpha$. Formally:

$$
\beta_{i}=\min \left(\left|\frac{\frac{p_{i}}{l_{i}}-\bar{a}}{\bar{a}}\right|,\left|\frac{\frac{p_{i}}{u_{i}}-\bar{a}}{\bar{a}}\right|\right), \quad \beta=\max _{i \in N} \beta_{i} .
$$

Empirical analysis shows that, in general, increasing $H$ results in a lower $\alpha$ ceteris paribus. The problem with small House sizes is that they imply a larger average constituency size. Divisibility issues can appear for smaller states that 
are only a few times as large as $\bar{a}$. It can happen that the average size of the constituencies of state $i$ is equally far away from $\bar{a}$ for both the lower and upper integer part of $\frac{P}{p_{i}}$, formally

$$
\frac{\frac{p_{i}}{l_{i}}-\bar{a}}{\bar{a}}=\frac{\bar{a}-\frac{p_{i}}{u_{i}}}{\bar{a}} .
$$
computation shows that, in general, if 3 holds, then $d_{i}=\frac{1}{2 l_{i}+1}$. The Table 1 summarizes the problematic state population sizes.

\begin{tabular}{ccl}
\hline$l_{i}-u_{i}$ & $p_{i}^{*}$ & \multicolumn{1}{c}{$\beta_{i}$} \\
\hline $1-2$ & $\frac{4}{3} \bar{a}$ & 0.333 \\
$2-3$ & $\frac{12}{5} \bar{a}$ & 0.2 \\
$3-4$ & $\frac{24}{7} \bar{a}$ & 0.143 \\
$4-5$ & $\frac{40}{9} \bar{a}$ & 0.111 \\
$5-6$ & $\frac{60}{11} \bar{a}$ & 0.091 \\
\hline
\end{tabular}

Table 1: Critical state populations regarding divisibility. The first column shows the lower and upper quotas, $p_{i}^{*}$ are the population levels where the minimal difference produced by these is maximal, and $\beta_{i}$ is the corresponding worst case value of the minimal difference.

In other words, if there is a state with population $\frac{4}{3}$ of the average con220 stituency size then $\alpha$ is at least $\frac{1}{3}$. For this value a lower $d$ cannot be adhered to. One way to overcome this is to increase the house size $H$ and thereby increase the number of constituencies allocated to each state, in particular, to the smallest state. Let $i$ denote the smallest state and

$$
\gamma \stackrel{\text { def }}{=} \begin{cases}\frac{1}{2 l_{i}+1} & \text { if } l_{i} \neq 0, \\ \infty & \text { if } l_{i}=0 .\end{cases}
$$

As the House size increases, $l_{i}$ increases, and therefore $\gamma$ decreases. Note 225 that $\gamma$ is an upper bound for $\beta$ but there is no obvious connection between $\gamma$ and $\alpha$. For instance, if we are able to distribute the seats according to the exact 
quota, then $\alpha$ is zero, but $\gamma$ can be high. However let $p_{1}, p_{2}=200$ and $p_{3}=600$ and let the House size equal to 7 . Then $\gamma=\frac{1}{3}$, but $\alpha \geq 0.4$. We will further analyze the relation of $\alpha, \beta$ and $\gamma$ in Section 5 using real data.

\subsection{Properties}

As we mentioned earlier, the quota and smallest maximum admissible departure properties have different objectives. An apportionment method that implements the latter will distribute less seats to a state than its lower quota if the maximum admissible departure can be lowered in this way. Large states serve as puffers where superfluous seats can be allocated or seats can be acquired if there are needed elsewhere as these do not change the average size of constituencies dramatically. Table 2 demonstrates this process.

\begin{tabular}{cc|ccc|ccc}
\hline \multicolumn{2}{c|}{ Method $\Rightarrow$} & \multicolumn{3}{|c|}{ Smallest max. adm. dep. } & \multicolumn{3}{c}{ quota } \\
\hline State & Population & seats & $\frac{p_{i}}{a_{i}}$ & $\delta_{i}$ & seats & $\frac{p_{i}}{a_{i}}$ & $\delta_{i}$ \\
\hline A & 26 & 3 & 8.666 & $-\mathbf{0 . 1 3 8}$ & 2 & 13 & $\mathbf{0 . 2 9 3}$ \\
B & 27 & 3 & 9 & -0.104 & 3 & 9 & -0.104 \\
C & 28 & 3 & 9.333 & -0.071 & 3 & 9.333 & -0.071 \\
D & 29 & 3 & 9.666 & -0.038 & 3 & 9.666 & -0.038 \\
E & 91 & 8 & 11.375 & 0.131 & 9 & 10.111 & 0.006 \\
\hline Total & 201 & 20 & 10.05 & & 20 & 10.05 \\
\hline
\end{tabular}

Table 2: quota vs. smallest maximum admissible departure. A simple example of 5 regions and 20 seats with the number of seats $a_{i}$, the population per seat $\frac{p_{i}}{a_{i}}$ and the difference from the average $\delta$.

In the above example the total population equals to 201 while the average constituency size is 10.05. If we insist on applying the quota then State E must receive at least 9 seats. As a result State A - the smallest one - gets only 2 . The voters in State A have the least influence, nearly $30 \%$ less than on average. On the other hand, if we apply the smallest maximum admissible departure property, State A gets an extra seat and the largest bias is reduced to $13.8 \%$. 
The next table shows an occurrence of population paradox when we try to

\begin{tabular}{c|ccc|ccc}
\hline State & Population & seats & $\delta_{i}$ & Population & seats & $\delta_{i}$ \\
\hline A & 69 & 3 & 0.114 & 69 & 3 & 0.003 \\
B & 70 & 3 & 0.130 & 80 & 4 & -0.127 \\
C & 150 & 8 & -0.091 & 172 & 7 & 0.071 \\
\hline Total & 289 & 14 & & 321 & 14 & \\
\hline
\end{tabular}

Table 3: Population paradox with smallest maximum admissible departure

Finally we note that the smallest maximum admissible departure property is not compatible with house-monotonicity either. An apportionment rule that minimizes the maximum admissible departure can produce the Alabamaparadox.

\begin{tabular}{ccc|ccc|cc}
\hline State & Population & Seats & \multicolumn{1}{c}{$\frac{p_{i}}{a_{i}}$} & $\delta_{i}$ & Seats & $\frac{p_{i}}{a_{i}}$ & \multicolumn{1}{c}{$\delta_{i}$} \\
\hline A & 69 & 3 & 23 & 0.114 & 4 & 17.250 & -0.104 \\
B & 70 & 3 & 23.333 & 0.130 & 4 & 17.500 & -0.091 \\
C & 150 & 8 & 18.750 & -0.091 & 7 & 21.428 & 0.112 \\
\hline Total & 289 & 14 & 20.642 & & 15 & 19.266 & \\
\hline
\end{tabular}

Table 4: House-monotonicity and smallest maximum admissible departure causes State C to lose a seat. State C is the largest state hence its average constituency size changes only a little when one of its seats is assigned elsewhere. A house-monotone allotment such as $\mathbf{a}=(3,4,8)$ would have a $19.3 \%$ as smallest maximum admissible departure almost twice as much as the allotment 
dinates where these vectors differ. Formally vector $x \in \mathbb{R}^{m}$ is lexicographically smaller than $y \in \mathbb{R}^{m}$ (denoted by $x \preceq y$ ) if $x \neq y$ and there exists a number $1 \leq j \leq m$ such that $x_{i}=y_{i}$ if $i<j$ and $x_{j}<y_{j}$. 
Returning to our model, given an apportionment problem $(\mathbf{p}, H)$ and an

Phase 2: If $l<H$ then for each $t=0,1 \ldots H-l-1$ do the following adjustment. Let $\mathbf{a}[t+1]=\mathbf{a}^{i+}[t]$ for $i \in\{1, \ldots, n\}$ such that $d_{i}\left(\mathbf{a}^{i+}[t]\right)$ is minimal.

If $l>H$ then for each $t=0,1 \ldots l-H-1$ do the following adjustment. Let $\mathbf{a}[t+1]=\mathbf{a}^{i-}[t]$ for $i \in\{1, \ldots, n\}$ such that $d_{i}\left(\mathbf{a}^{i-}[t]\right)$ is minimal.

310

That is, we first find a pre-allotment $\mathbf{a}[0]$ that is lexicographically minimal and then we simply increase (or decrease) the number of seats in a greedy way, we add (or remove) a seat to (or from) state $i$ if the increased difference is the smallest for this state. In what follows we show that these greedy adjustments lead to leximin pre-allotments in each step, and therefore a leximin allotment at the end of the process. 
Theorem 5. The greedy leximin algorithm results in the leximin solution for the apportionment problem.

Proof. If $\sum_{i=1}^{n} a_{i}[0]=l=H$ then $\mathbf{a}[0]$ is the leximin allotment, obviously. Since $a_{i}[0]=\left\lfloor\frac{p_{i}}{\bar{a}}\right\rfloor$ or $a_{i}[0]=\left\lceil\frac{p_{i}}{\bar{a}}\right\rceil$ for each state $i$, the difference $|l-H|$ must be less than or equal to $n$.

Suppose that $l<H$, the case of $l>H$ can be proved in a similar way. Let us show by induction for $t=0,1, \ldots, H-l$, that $\mathbf{a}[t]$ is the leximin pre-allotment when $l+t$ seats are available, so in particular, $\mathbf{a}[H-l]$ is the leximin allotment for the original problem. The statement is true for $t=0$, suppose that it is true for an arbitrary $t: 0 \leq t<H-l$ and let us verify the statement for $t+1$.

Suppose for a contradiction that there exists a pre-allotment $\mathbf{b}$ where the total number of seats allocated is $l+t+1$ and $\mathbf{b}$ is leximin among the pre-allotments with the same number of seats, so in particular, $\boldsymbol{\Delta}(\mathbf{b})$ is lexicographically smaller than $\boldsymbol{\Delta}(\mathbf{a}[t+1])$.

Let $\mathbf{a}[0]_{\leq}=\{\mathbf{a}: \mathbf{a}[0] \leq \mathbf{a}\}$, that is set of pre-allotments where each state has at least as many seats as in $\mathbf{a}[0]$. First we shall observe that for any $\mathbf{a} \in \mathbf{a}[0]_{\leq}$, $d_{i}(\mathbf{a})<d_{i}\left(\mathbf{a}^{i+}\right)$, i.e., when we increase the number of seats in any state $i$ the absolute difference from the average size in state $i$ can only increase. This implies that if $\mathbf{a}[0] \leq \mathbf{a} \leq \mathbf{a}^{\prime}$ and $\mathbf{a} \neq \mathbf{a}^{\prime}$ then $\boldsymbol{\Delta}(\mathbf{a}) \prec \boldsymbol{\Delta}\left(\mathbf{a}^{\prime}\right)$. The greedy algorithm allocates the remaining seats gradually, therefore $\mathbf{a}[0] \leq \mathbf{a}[1] \leq \cdots \leq \mathbf{a}[H-l]$. Furthermore, $b \in \mathbf{a}[0]_{\leq}$must hold, because if $b_{i}<a_{i}[0]$ for a state $i$ then there must be another state $j$ such that $b_{j}>a_{j}[0]$, and since $d_{i}(\mathbf{b})>d_{i}\left(\mathbf{b}^{i+}\right) \geq$ $d_{i}(\mathbf{a}[0])$ and $d_{j}(\mathbf{b})>d_{j}\left(\mathbf{b}^{j-}\right) \geq d_{j}(\mathbf{a}[0])$, we could decrease the departure of $\mathbf{b}$ from the average size in both states $i$ and $j$ by moving one seat from $j$ to $i$, contradicting to the optimality of $\mathbf{b}$.

First we prove that $\boldsymbol{\Delta}(\mathbf{a}[t]) \prec \boldsymbol{\Delta}(\mathbf{b})$. Let $i$ be a state where $b_{i}>a_{i}[t]$ (there must be such a state since $\mathbf{b}$ allocates one more seat than $\mathbf{a}[t]$ ). Then $\mathbf{a}[0] \leq \mathbf{b}^{i-} \leq \mathbf{b}$ implies $\boldsymbol{\Delta}\left(\mathbf{b}^{i-}\right) \prec \boldsymbol{\Delta}(\mathbf{b})$. Therefore $\boldsymbol{\Delta}(\mathbf{b}) \prec \boldsymbol{\Delta}(\mathbf{a}[t])$ would imply $\boldsymbol{\Delta}\left(\mathbf{b}^{i-}\right) \prec \boldsymbol{\Delta}(\mathbf{a}[t])$, which is in contradiction with our assumption since $\mathbf{b}^{i-}$ is an allotment with $l+t$ seats. 
Let us now assume that when adjusting the pre-allotment $\mathbf{a}[t]$ to $\mathbf{a}[t+1]$ in the greedy algorithm we increase the number of seats in country $i$. Suppose that the difference $d_{i}(\mathbf{a}[t+1])$ is the $r$ th largest, i.e., $d_{i}(\mathbf{a}[t+1])$ is the $r$ th entry of vector $\boldsymbol{\Delta}(\mathbf{a}[t+1])$. The first $r-1$ entries of $\boldsymbol{\Delta}(\mathbf{a}[t])$ and $\boldsymbol{\Delta}(\mathbf{a}[t+1])$ are the same, so $\boldsymbol{\Delta}(\mathbf{a}[t]) \prec \boldsymbol{\Delta}(\mathbf{b}) \prec \boldsymbol{\Delta}(\mathbf{a}[t+1])$ implies that the first $r-1$ entries of $\mathbf{b}$ are also the same, so in each of the corresponding $r-1$ states all these three pre-allotments assign the same number of seats (thus they are identical for these $r-1$ states). Regarding state $i$, it must be the case that $d_{i}(\mathbf{b}) \leq d_{i}(\mathbf{a}[t+1])$ (otherwise $\mathbf{b}$ would not be lexicographically smaller than $\mathbf{a}[t+1])$, therefore $b_{i} \leq a_{i}[t+1]$. From the latter it follows that among the rest of the $n-r$ states there must be one, say $j$, where $b_{j}>a_{j}[t+1]=a_{j}[t]$ since both $\mathbf{b}$ and $\mathbf{a}[t+1]$ allocate $l+t+1$ seats, and they are not identical. Therefore $b_{j} \geq a_{j}[t]+1$, which implies $d_{j}\left(\mathbf{a}[t]^{j+}\right) \leq d_{j}(\mathbf{b})$. But $\boldsymbol{\Delta}(\mathbf{b}) \prec \boldsymbol{\Delta}(\mathbf{a}[t+1])$ also implies $d_{j}\left(\mathbf{a}[t]^{j+}\right) \leq d_{j}(\mathbf{b})<d_{i}(\mathbf{a}[t+1])=d_{i}\left(\mathbf{a}[t]^{i+}\right)$, leading to a contradiction with the selection of $i$ in the greedy algorithm.

Note that both Phase 1 and Phase 2 can be conducted in $n^{2}$ steps, if one step means a comparison of two differences.

\section{Data Analysis}

In this section we first evaluate the 2011 Electoral Law of Hungary that triggered our interest in the recommendations of the Venice Commission at the first place. Then we look at the United States House of Representatives and the German Bundestag and discuss the allocation of seats according to the leximin method.

\subsection{Hungary}

The 2011 Electoral Law of Hungary drastically decreased the number of seats in the parliament and fixed the number of constituencies at 106. The law also proposed a seat distribution among the counties. Although the apportionment method was not provided, the law prescribed some principles for subsequent 
375

Venice Comission. The law requires that the difference between the population of any constituency and the average constituency size should be within $15 \%$. The only exception is if a constituency would extend over the county border or its connectivity could not be ensured. In these cases higher difference is 380 allowed, but if it ever exceeds $20 \%$ then a new allotment should be provided. Table 7 compares the seat distribution proposed by the law with the one that is produced by the leximin algorithm ${ }^{3}$.

\begin{tabular}{lc|cc|cc}
\hline \multirow{2}{*}{ County } & \multirow{2}{*}{ Voters } & \multicolumn{2}{c|}{ Seats } & \multicolumn{2}{c}{ Difference $\left(\delta_{i}\right)$} \\
\cline { 3 - 6 } & & law & leximin & law & leximin \\
\hline Budapest & 1407470 & $\mathbf{1 8}$ & $\mathbf{1 7}$ & $\mathbf{1}$ & $\mathbf{6 . 9 5}$ \\
Baranya & 325943 & 4 & 4 & 5.26 & 5.26 \\
Bács-Kiskun & 438352 & 6 & 6 & -5.63 & -5.63 \\
Békés & 308471 & 4 & 4 & -0.38 & -0.38 \\
Borsod-Abaúj-Zemplén & 567910 & 7 & 7 & 4.8 & 4.8 \\
Csongrád & 345945 & $\mathbf{4}$ & $\mathbf{5}$ & $\mathbf{1 1 . 7 2}$ & $-\mathbf{1 0 . 6 3}$ \\
Fejér & 351237 & 5 & 5 & -9.26 & -9.26 \\
Győr-Moson-Sopron & 364894 & 5 & 5 & -5.73 & -5.73 \\
Hajdú-Bihar & 439618 & 6 & 6 & -5.35 & -5.35 \\
Heves & 257490 & 3 & 3 & 10.87 & 10.87 \\
Jász-Nagykun-Szolnok & 324869 & 4 & 4 & 4.91 & 4.91 \\
Komárom-Esztergom & 255396 & 3 & 3 & 9.97 & 9.97 \\
Nógrád & 170463 & 2 & 2 & 10.1 & 10.10 \\
Pest & 973668 & 12 & 12 & 4.81 & 4.81 \\
Somogy & 268844 & 4 & 4 & -13.18 & -13.18 \\
Szabolcs-Szatmár-Bereg & 450556 & 6 & 6 & -3 & -3 \\
Tolna & 196751 & 3 & 3 & -15.28 & -15.28 \\
Vas & 215773 & 3 & 3 & -7.09 & -7.09 \\
& & & & &
\end{tabular}

\footnotetext{
${ }^{3}$ To calculate $\delta_{i}$ we used the demographic data of the 2010 election.
} 


\begin{tabular}{lc|cc|cc} 
Veszprém & 300081 & 4 & 4 & -3.09 & -3.09 \\
Zala & 242236 & 3 & 3 & 4.3 & 4.3 \\
\hline Total & 8205967 & 106 & 106 & & \\
\hline
\end{tabular}

Table 5: The seat distribution and the differences from the average district size by the Electoral Law and by the leximin algorithm

Note that only two out of 20 counties have a different number of seats allotted. The average constituency size in Heves County is 85830 which is $30.87 \%$ higher than the average constituency size of Tolna. Therefore voters in Tolna have $30.87 \%$ more influence than those living in Heves. If we allow $20 \%$ discrepancy from the average constituency size then the difference between voters' influence can be as high as $50 \%$. Interestingly, it is not these counties where the apportionment by law differs from the results of the 7 common methods calculated by Bodnár (2012), but Pest and Somogy.

\section{Upper bounds on the smallest maximum admissible departure}

The following figure shows how the smallest maximum admissible departure from the average constituency size $(\alpha)$ changes as we increase the House size from 50 to 180 . To calculate the smallest maximum admissible departure the leximin method was used.

Increasing House size indeed implies smaller $\alpha$, although it is far from being monotone. The upper bounds imposed by $\gamma$ are clearly visible. The graph never crosses $33.33 \%$, and for higher $H$ values the upper limits are $20 \%$ and $14.28 \%$. This implies that $\alpha$ coincides with $\beta$ in most of the cases. A deeper analysis shows that $\alpha=\beta$ is true for a broader range of $H$. From the $[50,400]$ interval there are only two exceptions, namely, when the House size equals to 87 and 88 . But even for these values it is true that $\alpha<\gamma$. Our conjecture is that for real life data $\alpha$ rarely differs from $\beta$, therefore $\gamma$ can be an effective upper bound for both. That means that if one would like to meet the Venice Commission's recommendation, then the House size should be set so high that the lower quota 


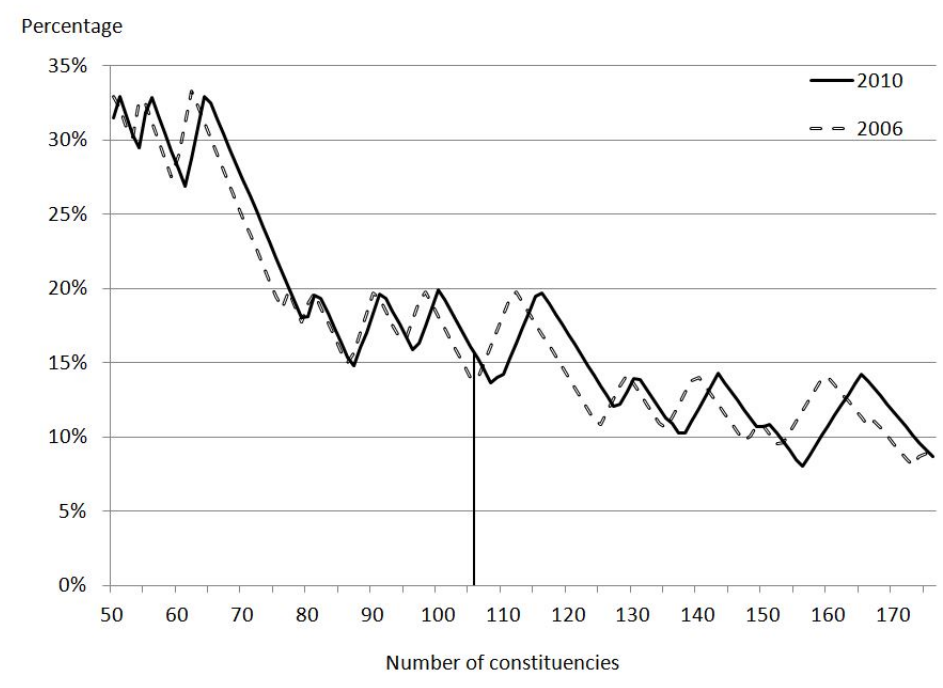

Figure 1: The decline of smallest maximum admissible departure compared to increasing House size using voter data from 2006 and 2010.

of the smallest county is at least 3 for the strict $15 \%$ limit.

Due to the demographic changes the local minimum of $\alpha$ shifted from 106 to 108 in four years. It can easily happen that in the near future 106 seats would mean the local maximum for $\alpha$. A solution for this issue would be to choose the House size from an interval rather than fixing it. Although this seems to lead to an unpredictable system, in reality it would imply only a minor change from one election to the next as there would be one or two counties that would receive extra seats or have to give up one.

\section{Monotonicity}

Figure 2 shows how frequently the Alabama-paradox occurs as the House size changes.

The anomaly occurs only in the two largest counties 4 As we mentioned earlier, the explanation is simple: large counties behave as puffers. They can store

\footnotetext{
${ }^{4}$ For higher House sizes the paradox occurs in the next largest county, Borsod-AbaújZemplén as well.
} 


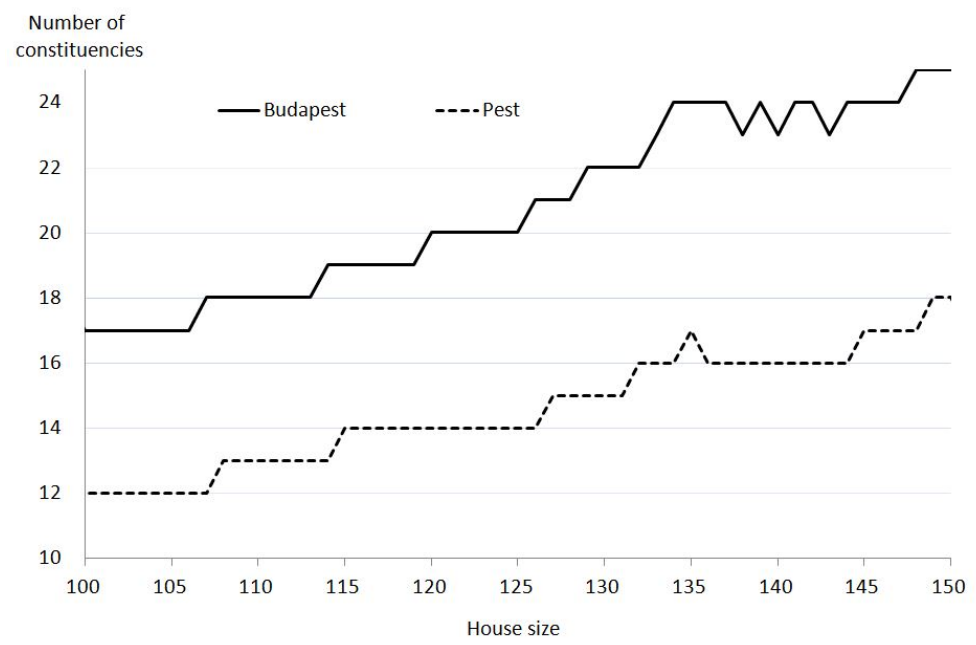

Figure 2: The number of constituencies in Budapest and in Pest county in view of House size constituencies without affecting the leximin ordering too much and 'borrow' seats for smaller counties that are crucial for the leximin ordering.

Changing the size of the regions

Finally, another way to lower the smallest maximum admissible departure is to increase the size of the administrative units that bundles the constituencies. Instead of counties we can use regions requiring only that no constituency extends over the region border. Table 6 summarizes the results for regions.

For instance, Northern Hungary consists of Borsod-Abaúj-Zemplén, Heves and Nógrád counties. By the law 7, 3 and 2 seats are assigned to them respectively, altogether 12. Heves produces the highest difference from the average: $10.87 \%$. However if we treat these three counties as one administrative unit then it receives 13 seats and the sizes of its constituencies will be 76605 , only $1.05 \%$ lower than the average. In this way Western Transdanubia generates the highest average $3.37 \%$ which is only a fraction of the $15.28 \%$ that Tolna county produces. 


\begin{tabular}{lc|cc|rc}
\hline \multirow{2}{*}{ Region } & \multirow{2}{*}{ Voters } & \multicolumn{2}{|c|}{ Number of seats } & \multicolumn{2}{c}{ Difference. (\%) } \\
\cline { 3 - 6 } & & law & leximin & law & leximin \\
\hline Northern Hungary & 995863 & 12 & 13 & 10.87 & 1.05 \\
Northern Great Plain & 1215043 & 16 & 16 & 5.35 & 1.90 \\
Southern Great Plain & 1092768 & 14 & 14 & 11.72 & 0.83 \\
Central Hungary & 2381138 & 30 & 30 & 4.81 & 2.53 \\
Central Transdanubia & 906714 & 12 & 12 & 9.97 & 2.40 \\
Western Transdanubia & 822903 & 11 & 11 & 7.09 & 3.37 \\
Southern Transdanubia & 791538 & 11 & 10 & 15.28 & 2.25 \\
\hline Total & 8205967 & 106 & 106 & & \\
\hline
\end{tabular}

Table 6: The optimal seat distribution where no constituency extends over the region border

\subsection{The German Bundestag}

Similarly to the Hungarian election system, Germans voters may cast two votes 5 . The first vote decides - with simple relative majority - the fate of 299 seats. With this vote the residents can choose their candidate of choice in their own district. The second vote is the more important one, with it the voters can decide which party to support from the regional electoral list. Based on the proportion of second votes, the rest of the mandates - another 299 seats - are distributed to the parties who have achieved at least 5 percent of valid second votes. It may happen that according to the second votes a party should receive less seats than it actually gained with the first votes. In such cases the party is allowed to keep the mandates that exceed its proportional share - these are the so called overhang seats. Indeed, after the 2013 elections the Bundestag was formed with 631 representatives, and this number can theoretically be as high as 897 .

Here we analyze the seats that are elected directly with the first votes using data from the 2013 elections (?). The average constituency size is 207180 .

\footnotetext{
${ }^{5}$ The resemblance is not by chance. The German election system was a case model when the Hungarian Electoral Law was first scripted in 1989.
} 
450 change the enormous bias caused by Bremen, where the average constituency size is $241912(+16.76 \%)$. Furthermore, the constituencies of Bremen are not of the same size - the larger of the two has 256547 voters $(+23.83 \%)$. Interestingly, this does not even produce the largest difference. The Hamburg-Mitte district 455 862 voters $(+23.98 \%)$, while Deggendorf in Bayern has 155082 or $-25.15 \%$ that is even larger difference. These examples show that creating equally sized constituencies within an administrative region may cause further complications. For more on the apportionment issues related to the German election system 460 see (?).

\begin{tabular}{|c|c|c|c|c|c|}
\hline \multirow{2}{*}{ County } & \multirow{2}{*}{ Voters } & \multicolumn{2}{|c|}{ Seats } & \multicolumn{2}{|c|}{ Difference $\left(\delta_{i}\right)$} \\
\hline & & law & leximin & law & leximin \\
\hline Baden-Württemberg & 7689895 & 38 & 37 & -2.32 & 0.32 \\
\hline Bayern & 9472738 & 45 & 46 & 1.60 & -0.60 \\
\hline Berlin & 2505718 & 12 & 12 & 0.79 & 0.79 \\
\hline Brandenburg & 2065944 & 10 & 10 & -0.28 & -0.28 \\
\hline Bremen & 483823 & 2 & 2 & 16.76 & 16.76 \\
\hline Hamburg & 1281918 & 6 & 6 & 3.12 & 3.12 \\
\hline Hessen & 4413271 & 22 & 21 & -3.17 & 1.44 \\
\hline Mecklenburg-Vorpommern & 1350705 & 6 & 7 & 8.66 & -6.86 \\
\hline Niedersachsen & 6117473 & 30 & 30 & -1.58 & -1.58 \\
\hline Nordrhein-Westfalen & 13253554 & 64 & 64 & -0.05 & -0.05 \\
\hline Rheinland-Pfalz & 3092424 & 15 & 15 & -0.49 & -0.49 \\
\hline Saarland & 796072 & 4 & 4 & -3.94 & -3.94 \\
\hline Sachsen & 3406430 & 16 & 16 & 2.76 & 2.76 \\
\hline Sachsen-Anhalt & 1930880 & 9 & 9 & 3.55 & 3.55 \\
\hline Schleswig-Holstein & 2251796 & 11 & 11 & -1.19 & -1.19 \\
\hline Thüringen & 1834259 & 9 & 9 & -1.63 & -1.63 \\
\hline Total & 61946900 & 299 & 299 & & \\
\hline
\end{tabular}


Table 7: The seat distribution and the differences from the average district size in the Bundestag in the 2013 elections compared with the same data induced by the leximin algorithm

\subsection{The United States House of Representatives}

Much of the literature of apportionment is based on the problems encountered at the regular updates of seat allocation in the United States House of Representatives. In the following we explain how and why our recommended allocation for the US House of Representatives differs and how the current method fares in general when compared with our leximin approach.

\subsubsection{The leximin vs. the equal proportions method}

To further illustrate the properties of the leximin rule let us compare it with the equal proportion (EP) method (Huntington, 1921), that is used to distribute the seats of the US House of Representatives. The method of Equal Proportions first distributes one seat to each state, then the remaining seats are allocated one at a time, to the state with the highest 'priority number'. Priority of state $i$ is determined by the formula $\frac{p_{i}}{\sqrt{k(k+1)}}$, where $k$ runs from 1 until all the seats are distributed. It is a house-monotone apportionment rule, but it does not satisfy quota (although it rarely produces a non-quota solution). The table of the apportionment of the 2010 US census compared with the result of the leximin algorithm can be found in the appendix Appendix A Figure 3 provides a visual summary.

The two resulting allotments are very similar. In fact there are only two states where the solutions differ: California and Montana. The scenario is the same we have seen before. The largest state lends a seat to one of the smaller ones and the smallest maximum admissible departure drops by almost $10 \%$. It is quite surprising that the voters of Rhode Island - where the average constituency size is the smallest - have $88 \%$ more influence than the voters of ${ }_{485}$ Montana. Although the leximin allotment reduces this gap somewhat, the only 


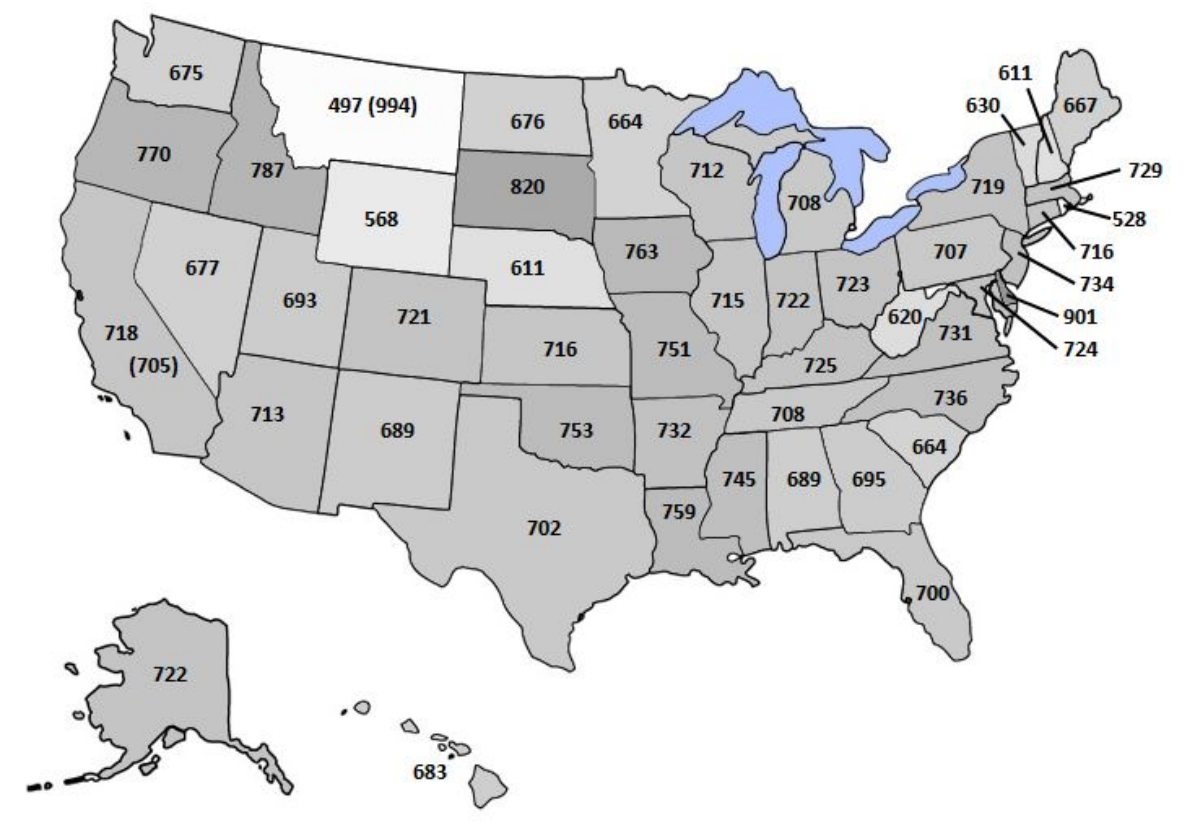

Figure 3: The number of citizens per representative according to the leximin method (in thousands). In parentheses the same figure for the EP method (where different). Note the dramatic swing for Montana.

efficient solution would be to drastically increase the House size. As there are 50 states and seven among them end up with only one representative each, the size of the House of Representatives can be considered rather small. Figure 4 shows how the smallest maximum admissible departure changes for higher House sizes.

Smallest maximum admissible departures

As it can be anticipated the smallest maximum admissible departure of the leximin solution never exceeds $33.3 \%$ however for the EP there is no such limit. To make certain that the smallest maximum admissible departure is below $20 \%$ we have to ensure that the smallest state, Wyoming a) receives at least two representatives and b) the constituency size obtained this way is within $20 \%$ of the average. A simple calculation shows that the smallest House size that guarantees these two criteria is 871 - a little more than twice its current size. As it is unlikely that the House of Representatives will be expanded in such 


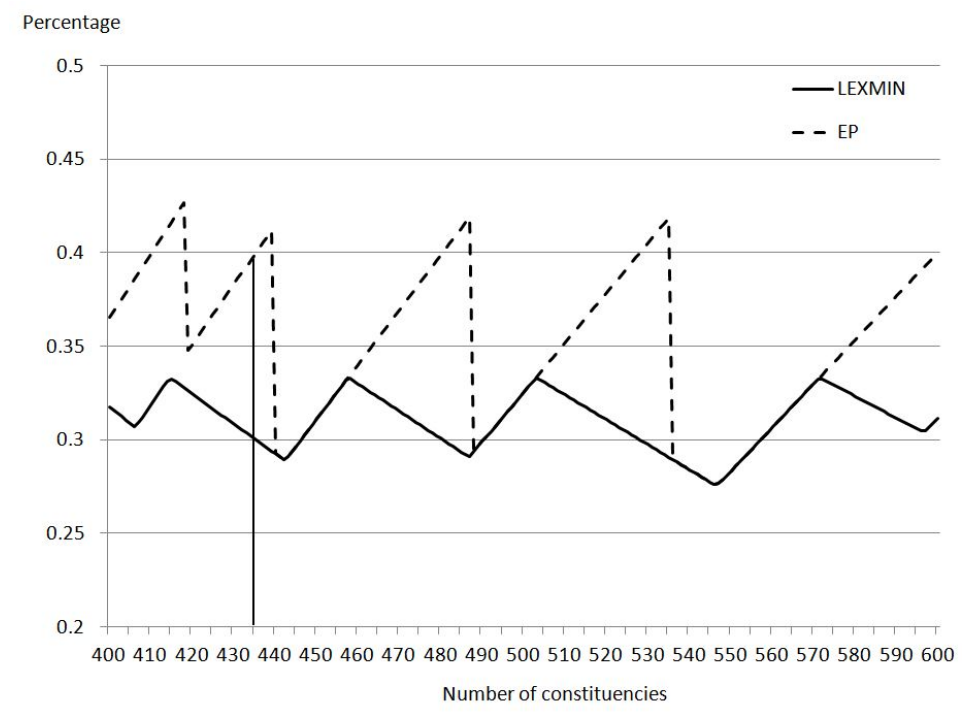

Figure 4: The smallest maximum admissible departure in view of the House size

fashion the influence of the voters will continue to vary from state to state. A temporary solution would be to increase the number of representatives by seven. The smallest maximum admissible departure for both the leximin and the EP solution meets its minimum at House size 442. In that case the highest gap between voters influence is 'only' $55.19 \%$.

\section{Conclusion}

More and more countries adopt fairness measures in their electoral law that is based on, or similar to the recommendation of the Venice Commission (2002a). Based on the smallest maximum admissible departure property we introduce the well-defined Leximin Rule.

Our apportionment method is not the first. The problem of apportionment goes centuries back, the problem has been around ever since the new member states and population changes required a new seat allocation in the US House of Representatives. Balinski and Young (1982) give an illuminating theoretical and historical overview of the problem of apportionment and the political debates 
that arose due to it. Methods like Hamilton's (also called the Method of Largest Remainders), Jefferson's (Method of Greatest Divisors, but in Europe often referenced as the d'Hondt method), or the Huntingdon-Hill or Equal Proportions method, the currently used method in the US House of Representatives have all been developed as responses to practical problems with apportionment such as the emergence of one or another paradox. Lauwers and Van Puyenbroeck (2006) compare some of these methods.

Apportionment problems are most often used for allocating seats among administrative or political regions based on the population size of these regions: states in the US House of Representatives, countries in the EU parliament and so on. Our paper focuses on these applications. Apportionment is also used for the allotment of seats to parties based on the outcome of an election, in fact, sometimes both segmentations appear at the same time; the so-called biapportionment is used in some European countries and the problem has been studied by Demange (2012) and Serafini and Simeone (2012).

The Lexicographic Rule is, to the best of our knowledge, an original apportionment method, although lexicographic solution concepts have already been proposed by Gambarelli (1999) and Gambarelli and Palestini (2007). The closest model is by Serafini and Simeone (2012), where the relative differences from the target quotas are lexicographically minimized in the bi-apportionment problem. However, their target quotas are not the same as ours (when restricted to 535 a one-dimensional case), and their methods proposed are more complex, since they are designed for the more general bi-apportionment problem.

There are also papers on minimizing the relative difference over pairs of constituencies. Burt and Harris (1963) proposed this concept in for the US House of Representatives, but then it got criticized by Gilbert and Schatz (1964). 540 A recent overview on this concept is given by Edelman (2006). Our problem is different from this one, and it is easy to construct an example where the solutions minimizing the relative difference of any two constituencies and the maximum departure from the average size differ. So far, it seems, none of these models are compatible with the recommendation of the Venice Commission. 
The smallest maximum admissible departure property is very natural and provides greater equality among citizens concerning their voting power than other apportionment principles. Unfortunately, the property and therefore the Leximin Rule turn out to be incompatible with the quota, the population- and house-monotonicities over the class of apportionment problems, so that the $\mathrm{Al}$ abama and population paradoxes may arise when using it. It seems we have just introduced a new method that fails all existing industry standards! Indeed these properties emerged over century-long debates over the election rules for the US House of Representatives and cannot be just ignored. On the other hand the proposal of the Venice Commission is a very natural and plausible one, it is comparable to the quota, while the violations of monotonicity are hardly surprising in an integer problem. The fact that more and more countries consider the smallest maximum admissible departure property as its de facto standard to evaluate, improve and design apportionment among regions may be seen as an indication that this is a natural and valid property whose incompatibility with some old thoughts from the New World is interesting to be aware of, but is perhaps time to update them in a representative democracy. And finally, a third reading is just to note the emergence of two incompatible schools of apportionment that may coexist thanks to minor differences in our understanding of representative democracy.

\section{Acknowledgements}

The authors thank the comments of an anonymous refereee and Friedrich Pukelsheim from the University of Augsburg and Attila Tasnádi from the Corvinus University and all the participants of the Mathematics of Electoral Systems at Corvinus University for the helpful suggestions. The authors acknowledge the support of the 'Momentum' Programme (LP-004/2010) and the OTKA grants K108383 and K109354. 
Appendix A. The seat distribution of the US House of Representatives by the equal proportion method and by the leximin algorithm

\begin{tabular}{|c|c|c|c|c|c|}
\hline \multirow{2}{*}{ State } & \multirow{2}{*}{ Voters } & \multicolumn{2}{|c|}{ Number of seats } & \multicolumn{2}{|c|}{ Difference (\%) } \\
\hline & & $\mathrm{EP}$ & leximin & $\mathrm{EP}$ & leximin \\
\hline Alabama & 4802982 & 7 & 7 & 3.46 & 3.46 \\
\hline Alaska & 721523 & 1 & 1 & 1.51 & 1.51 \\
\hline Arizona & 6412700 & 9 & 9 & 0.24 & 0.24 \\
\hline Arkansas & 2926229 & 4 & 4 & 2.92 & 2.92 \\
\hline California & 37341989 & 53 & 52 & 0.87 & 1.03 \\
\hline Colorado & 5044930 & 7 & 7 & 1.39 & 1.39 \\
\hline Connecticut & 3581628 & 5 & 5 & 0.78 & 0.78 \\
\hline Delaware & 900877 & 1 & 1 & 26.74 & 26.74 \\
\hline Florida & 18900773 & 27 & 27 & 1.51 & 1.51 \\
\hline Georgia & 9727566 & 14 & 14 & 2.24 & 2.24 \\
\hline Hawaii & 1366862 & 2 & 2 & 3.84 & 3.84 \\
\hline Idaho & 1573499 & 2 & 2 & 10.69 & 10.69 \\
\hline Illinois & 12864380 & 18 & 18 & 0.55 & 0.55 \\
\hline Indiana & 6501582 & 9 & 9 & 1.63 & 1.63 \\
\hline Iowa & 3053787 & 4 & 4 & 7.41 & 7.41 \\
\hline Kansas & 2863813 & 4 & 4 & 0.72 & 0.72 \\
\hline Kentucky & 4350606 & 6 & 6 & 2.01 & 2.01 \\
\hline Louisiana & 4553962 & 6 & 6 & 6.78 & 6.78 \\
\hline Maine & 1333074 & 2 & 2 & 6.22 & 6.22 \\
\hline Maryland & 5789929 & 8 & 8 & 1.82 & 1.82 \\
\hline Massachusetts & 6559644 & 9 & 9 & 2.54 & 2.54 \\
\hline Michigan & 9911626 & 14 & 14 & 0.39 & 0.39 \\
\hline Minnesota & 5314879 & 8 & 8 & 6.52 & 6.52 \\
\hline Mississippi & 2978240 & 4 & 4 & 4.75 & 4.75 \\
\hline
\end{tabular}




\begin{tabular}{lc|cc|rr}
\hline Missouri & 6011478 & 8 & 8 & 5.72 & 5.72 \\
\hline Montana & $\mathbf{9 9 4 4 1 6}$ & $\mathbf{1}$ & $\mathbf{2}$ & $\mathbf{3 9 . 9 0}$ & $\mathbf{3 0 . 0 4}$ \\
\hline Nebraska & 1831825 & 3 & 3 & 14.09 & 14.09 \\
\hline Nevada & 2709432 & 4 & 4 & 4.70 & 4.70 \\
\hline New Hampshire & 1321445 & 2 & 2 & 7.04 & 7.04 \\
\hline New Jersey & 8807501 & 12 & 12 & 3.26 & 3.26 \\
\hline New Mexico & 2067273 & 3 & 3 & 3.04 & 3.04 \\
\hline New York & 19421055 & 27 & 27 & 1.20 & 1.20 \\
\hline North Carolina & 9565781 & 13 & 13 & 3.52 & 3.52 \\
\hline North Dakota & 675905 & 1 & 1 & 4.90 & 4.90 \\
\hline Ohio & 11568495 & 16 & 16 & 1.72 & 1.72 \\
\hline Oklahoma & 3764882 & 5 & 5 & 5.93 & 5.93 \\
\hline Oregon & 3848606 & 5 & 5 & 8.29 & 8.29 \\
\hline Pennsylvania & 12734905 & 18 & 18 & 0.46 & 0.46 \\
\hline Rhode Island & 1055247 & 2 & 2 & 25.76 & 25.76 \\
\hline South Carolina & 4645975 & 7 & 7 & 6.62 & 6.62 \\
\hline South Dakota & 819761 & 1 & 1 & 15.33 & 15.33 \\
\hline Tennessee & 6375431 & 9 & 9 & 0.33 & 0.33 \\
\hline Texas & 25268418 & 36 & 36 & 1.24 & 1.24 \\
\hline Utah & 2770765 & 4 & 4 & 2.54 & 2.54 \\
\hline Vermont & 630337 & 1 & 1 & 11.31 & 11.31 \\
\hline Virginia & 8037736 & 11 & 11 & 2.80 & 2.80 \\
\hline Washington & 6753369 & 10 & 10 & 4.98 & 4.98 \\
\hline West Virginia & 1859815 & 3 & 3 & 12.77 & 12.77 \\
\hline Wisconsin & 5698230 & 8 & 8 & 0.21 & 0.21 \\
\hline Wyoming & 568300 & 1 & 1 & 20.04 & 20.04 \\
\hline Total & 409353 & 435 & max $: 39.9$ & max $: 30.04$ \\
\hline
\end{tabular}

575 Balinski, M., Johnston, R., McLean, I., Young, P., Cummine, A., 2010. Drawing a New Constituency Map for the United Kingdom. Technical Report. British 
Academy, Policy Centre.

Balinski, M., Young, H.P., 1975. The quota method of apportionment. American Mathematical Monthly 82, 701-730.

Balinski, M., Young, H.P., 1982. Fair Representation: Meeting the Ideal of One Man, One Vote. Yale University Press, New Haven.

Banzhaf, J.F., 1965. Weighted voting doesn't work: A mathematical analysis. Rutgers Law Review 19, 317-343.

Biró, P., Kóczy, L.A., Sziklai, B., 2012. Választókörzetek igazságosan? Közgazdasági Szemle 59, 1165-1186.

Bodnár, E., 2012. Alkotmányjogi dilemmák az új országgyűlési választási törvénnyel kapcsolatban. Közjogi Szemle 5, 40-48.

Burt, O.R., Harris, C.C., 1963. Apportionment of the US House of Representatives: A minimum range, integer solution, allocation problem. Operations Research 11, 648-652.

Chambers, C.P., Miller, A.D., 2013. Measuring legislative boundaries. Mathematical Social Sciences, $1-8$.

Demange, G., 2012. On party-proportional representation under district distortions. Mathematical Social Sciences 63, 181-191.

Edelman, P.H., 2006. Minimum Total Deviation Apportionments, in: Simeone, B., Pukelsheim, F. (Eds.), Mathematics and Democracy. Springer, Berlin Heidelberg, pp. 55-64.

Felsenthal, D.S., Machover, M., 1998. The Measurement of Voting Power: Theory and Practice, Problems and Paradoxes. Edward Elgar, Cheltenham. tion 8, 441-461. 
Gambarelli, G., Palestini, A., 2007. Minimax Multi-District Apportionments. Homo Oeconomicus 24, 335-356.

Gilbert, E.J., Schatz, J.A., 1964. An Ill-Conceived Proposal for apportionment of the US House of Representatives. Operations Research 12, 768-773.

Grimmett, G.R., 2012. European apportionment via the Cambridge Compromise. Mathematical Social Sciences 63, 68-73.

Grimmett, G.R., Oelbermann, K.F., Pukelsheim, F., 2011. A power-weighted variant of the EU27 Cambridge Compromise. ArXiv 1108. arXiv:1108.1315

Gul, F., Pesendorfer, W., 2010. Strategic redistricting. American Economic Review 100, 1616-1641.

Handley, L., 2007. Boundary Delimitation, in: Challenging the Norms and Standards of Election Administration. IFES, pp. 59-74.

Huntington, E., 1921. The mathematical theory of the apportionment of representatives. Proceedings of the National Academy of Sciences of the United States of America 7, 123-127.

Kóczy, L.A., 2011. Beyond Lisbon: Demographic trends and voting power in the European Union Council of Ministers. Mathematical Social Sciences 63, $158-152$.

Koriyama, Y., Laslier, J.F., Macé, A., Treibich, R., 2013. Optimal apportionment. Journal of Political Economy 121, 584-608.

Kubiak, W., 2009. Proportional Optimization and Fairness. Springer.

Laslier, J.F., 2012. Why not proportional? Mathematical Social Sciences 63, 90-93. Is Between the Adams Method and the Jefferson Method. Mathematics of Operations Research 31, 390-397. 
Lauwers, L., Van Puyenbroeck, T., 2008. Minimally Disproportional Representation: Generalized Entropy and Stolarsky Mean-Divisor Methods of Apportionment. Working Papers 2008/24. Hogeschool-Universiteit Brussel, Faculteit Economie en Management.

OSCE/ODIHR, 2011. Estonia Parliamentary Elections 6 March 2011. Election Assessment Mission Report. Organization for Security and Co-operation in Europe, Office for Democratic Institutions and Human Rights. Warsaw.

Penrose, L.S., 1946. The elementary statistics of majority voting. Journal of the Royal Statistical Society 109, 53-57.

Pukelsheim, F., 2007. Putting Citizens First : Representation and Power in the European Union, in: Cichocki, M., Życzkowski, K. (Eds.), Institutional Design and Voting Power in the European Union. Ashgate, London. chapter 14, pp. 235-253.

Pukelsheim, F., 2014. Proportional Representation.

Rose, R., Bernhagen, P., Borz, G., 2012. Evaluating competing criteria for allocating parliamentary seats. Mathematical Social Sciences 63, 85-89.

Serafini, P., Simeone, B., 2012. Parametric maximum flow methods for minimax approximation of target quotas in biproportional apportionment. Networks 59, 191-208.

Shapley, L.S., Shubik, M., 1954. A method for evaluating the distribution of power in a committee system. American Political Science Review 48, 787-792.

Venice Commission, 2002a. Code of Good Practice in Electoral Matters. CDL650 AD 23, 1-33.

Venice Commission, 2002b. Opinion on the Unified election Code of Georgia. CDL-AD 9, 1-19. 
Venice Commission, OSCE/ODIHR, 2011. On the Electoral Law and the Electoral Practice of Albania. Joint Opinion. Venice Commission and Organization for Security and Co-operation in Europe, Office for Democratic Institutions and Human Rights. Strasbourg. 